\title{
Modelling spatial and temporal road thermal climatology in rural and urban areas using a GIS
}

\author{
Andrew V. Bradley ${ }^{1}$, John E. Thornes ${ }^{1, *}{ }^{,}$Lee Chapman ${ }^{1}$, David Unwin ${ }^{2}$, Melanie Roy ${ }^{2}$ \\ ${ }^{1}$ School of Geography and Environmental Sciences, University of Birmingham, Edgbaston, Birmingham B15 2TT, \\ United Kingdom \\ ${ }^{2}$ School of Geography, Birkbeck College London, 7-15 Gresse St, London, W1T 1 LL, United Kingdom
}

\begin{abstract}
A 1-D road surface energy balance model was modified to account for the geographical variables of latitude, optical depth, sky-view factor, slope and slope orientation for the West Midlands (UK). The physical variables of albedo, emissivity and surface roughness are also included. Using a satellite land cover classification, aided by a field analysis of urban canyon characteristics, it was possible to estimate the spatial variation of surface variables across the West Midlands. Spatial analysis of the topography was achieved using a Geographical Information System (GIS) database which calculated values at $1 \mathrm{~km}^{2}$ resolution for the geographical variables. This enabled a spatial and temporal analysis of road surface temperatures (retrospectively) across the West Midlands. Sensitivity analysis shows that the geographical variables which have the most significant influence on the model are slope angle and sky-view factor. Validation of the model (West Midlands grid model, WMG) against actual road surface temperature for 15 road weather sensors distributed around the West Midlands, for February 2000, gave $\mathrm{R}^{2}$ values as high as 0.84 ; however regression indicated that for 79 nights in the period December 1999 to February 2000 the model overestimated the minimum road surface temperature with a bias of $0.65^{\circ} \mathrm{C}\left(\mathrm{RMSE} 2.07^{\circ} \mathrm{C}\right)$, as opposed to the Met Office model $(\mathrm{MOM})$, which underestimated with a bias of $-2.03^{\circ} \mathrm{C}$ (RMSE $3.09^{\circ} \mathrm{C}$ ). Time slices of the model output, covering an area of $2400 \mathrm{~km}^{2}$, show the development of a surface urban heat island in the West Midlands. The intensity of the modelled heat island is sensitive to the values used for the sky-view factor in the rural areas surrounding the urban conurbation. Winter solstice heat island intensity for calm clear nights in the West Midlands is calculated to be $4.7^{\circ} \mathrm{C}$. The structure of the heat island suggests that current Open Road weather forecast zones are not applicable in simulated clear calm conditions because of the wide range of road surface temperatures caused by the degree of urbanisation.
\end{abstract}

KEY WORDS: Urban climate - Road surface temperature - Geographical Information System • Sky-view factors $\cdot$ Road weather forecasts

\section{INTRODUCTION}

Provision for a road surface temperature forecast in the winter months is essential for highway engineers to determine the likelihood of ice formation on their roads, allowing cost effective salting decisions. Initially in the 1980s the installation of road surface sensors enabled the detection of slippery conditions at a few sampled locations, but as it takes several hours to salt a

${ }^{*}$ Corresponding author. E-mail: j.e.thornes@bham.ac.uk road network, a method was required to predict road surface temperatures several hours in advance. With the development of thermal mapping, numerical road energy balance modelling and the installation of road weather information systems (RWIS), it became possible in the 1990s to predict road conditions, up to $24 \mathrm{~h}$ in advance, relative to the sensor sites (Thornes et al. 1983, Thornes 1984, Rayer 1987, Thornes \& Shao 1991, Gustavsson \& Bogren 1993).

In the United Kingdom, the decision to salt a road network is based on a service called Open Road (OR) 
provided by the UK Met Office or the equivalent provided by a small number of private weather companies. The country is divided up into a number of individual climate zones (typically $200 \mathrm{~km}^{2}$ ), each with a road weather sensor. Each climate zone receives a tailored $24 \mathrm{~h}$ road condition forecast. However the climate zones have been defined subjectively and have fixed boundaries whatever the weather conditions. There is a need to provide flexible climate zones that are defined objectively on a night-by-night basis. In urban areas, such as the West Midlands (UK), a conurbation is likely to cause an urban heat island (UHI). The UHI is caused primarily by the radiative contrast between the rural and urban surfaces, which is most noticeable under calm, clear weather conditions. Forecasts provided by OR do not directly allow for UHI generation because the forecast zones do not distinguish clearly between urban and rural areas. The model described in this study (West Midlands Grid model, WMG) aims to forecast road surface temperature (RST) variations spatially and temporally, at $1 \mathrm{~km}^{2}$ resolution for an area of $2400 \mathrm{~km}^{2}$, over the West Midlands. This provides 2400 forecasts of RST compared to the 7 currently provided by OR. A spatial display of the model output allows assessment of the variation and timing of surface minima and examination of the applicability of the forecast zones.

The model calculates RST using the equilibrium temperature concept. There is only 1 temperature that will balance the net all-wave radiation flux, the latent heat flux plus the sensible heat flux and the heat flux from the ground (Thornes 1984). Several variables are needed to model each flux. The model used in this study concentrates on albedo, emissivity, roughness and sky-view factor (SVF).

The variation in albedo determines the reflection of short wave (SW) radiation. The emissivity of the surface influences the release of heat, or long wave (LW) radiation from the surface. The roughness of the surface influences vertical mixing between the surface and the air. The SVF is the calculated proportion of sky to buildings and/or vegetation, and it varies between zero (when no sky is visible, e.g. in a tunnel) and 1 (in an open area where the whole sky is visible). The SVF has 2 main influences on RST. The first is a decrease in SW radiation, and therefore $\mathrm{RST}$, with decreasing SVF, caused by shading of direct sun. The second is the effective absorption of LW radiation emitted by the surface, e.g. by buildings which prevent heat loss at night. Also the downward flux of LW radiation from the sky and buildings is effectively trapped. Hence a low SVF will keep roads relatively warm at night and, overall, a low SVF will dampen the diurnal change of RST. SVFs measured in the centre of cities have been related to the intensity of UHIs by Oke (1981): greatest intensities occur with lower, more enclosed SVFs where urban canyons are deeper. Bärring et al. (1985) describe how canyon geometry represented by SVF is closely related to RSTs inferred from thermal infra-red images. Previously it has been difficult to measure SVFs in sufficient quantity, so terms including 'shadow ratio' (Outcalt 1971, Greene 1980) and height/width ratios (Arnfield 1990, Swaid 1993, Mills 1997) have been used in urban canyon modelling. The model used in this paper includes SVFs, which can now be sampled rapidly and in great numbers from field measurements (Postgård 2000, Chapman et al. 2001, Grimmond et al. 2001).

The albedo and emissivity vary according to the material composition of the surface elements, such as buildings, trees, roads and hedges. Roughness and SVF are related to the density and dimensions of these elements. In the case of the West Midlands, the degree of urbanisation through the city-centre, residential and rural areas is highly variable, so there is a corresponding variation in surface elements. It follows that the surface energy budget is extremely variable, and the model aims to simulate this. Because individual urban canyon elements have their own values for the variables albedo, emissivity and roughness length, the density and proximity of these urban canyon elements must be estimated.

To measure every individual element for $2400 \mathrm{~km}^{2}$ would be an impossible process. A method has to be developed to quantify this variation over a large area (Tapper et al. 1981, Grimmond et al. 2001). The method assumes similar elements are often found in close proximity, so a change in elements results in a change in land cover, which in turn affects the variables. A satellite image was used to identify land cover classes from the variation in surface reflectance. Utilising the digital imagery, non adjacent similar areas could be identified and grouped together in the same class. From fieldwork in each land cover class, the dimensions and fabric of a typical urban canyon are estimated and extrapolated over the West Midlands study area.

\section{METHOD}

\subsection{Modifications to the energy balance model}

The forecast model (Thornes 1984, Thornes \& Shao 1991) was originally developed from a numerical energy balance model described by Outcalt (1971), in order to calculate RSTs for site-specific locations. The forecast model relies on several meteorological inputs for each climate zone and a range of local geographical factors. In order to forecast for 2400 grid cells covering the West Midlands, a number of alterations were necessary. 
The model is built to receive noon values of RST, air temperature, wind speed, relative humidity, cloud type and cloud amount. The same meteorological input data was used for all 2400 grid squares. Forecast values for the next $24 \mathrm{~h}$ were imported, and the model was brought into line with the Met Office OR forecasts, which are based on 3 hourly forecast values of air temperature, dew point, wind speed, cloud and precipitation. Fig. 1 shows the location of the West Midlands, the local topography and the location of the road weather sites used in this study.

\subsubsection{Geographic data}

Latitude. Latitude has an effect on the angle of incidence of incoming solar radiation; it was set at $51.0^{\circ}$ in the original model. Since the model resolution was set at $1 \mathrm{~km}$, a difference of $0^{\circ} 0^{\prime} 32.76 "$ was applied between each row of the $2400 \mathrm{~km}^{2}$ grid between latitudes $52^{\circ} 41^{\prime} 04.70^{\prime \prime}$ and $52^{\circ} 19^{\prime} 47.00^{\prime \prime}$.

Inclusion of SVF. The inclusion of the SVF has a differing influence on incoming and outgoing radiation.

Incoming SW radiation - For incoming radiation, the RST at a forecast site is influenced by the effect of shadowing, particularly towards sunrise and sunset (Bogren et al. 2000). This is influenced by the artificial horizon created by obstructions of buildings and trees. The main effect of this is that between true sunrise and sunset when the sun is below the artificial horizon the site in question does not receive any direct beam radiation. This needs to be accounted for in the model. In reality, each sky-view is very site specific, and it is too complex to represent a common artificial horizon for an individual $\mathrm{km}^{2}$. A calculation was devised to produce a representative sky-view or an artificial horizon for each $\mathrm{km}^{2}$ represented in the model. SVF horizons were simulated using infra-red measurements (Postgård 2000), assuming that the sky-view was analogous to a bowl as described by Oke (1987). This leads to the simulation of a 'chimney'-style canyon as opposed to a 'passage' canyon, which has an effect on the timing and duration of direct and diffuse radiation, particularly if the canyon is not north-south orientated. Fig. 2 demonstrates this. The top of each circle represents 12:00 h on the $22 \mathrm{De}-$ cember, the open arrow represents the effective sunrise, the filled arrow represents the effective sunset. Since the model only received input for SVF and a value corresponding to orientation of the canyon, a method to simulate the parallel uniform canyon was required. This was achieved by the use of a sixth-order polynomial which was the best fit curve to empirically derived SVF using software developed by McClean (1993). The polynomial is a good fit $\left(\mathrm{R}^{2}=0.9986\right)$ to the

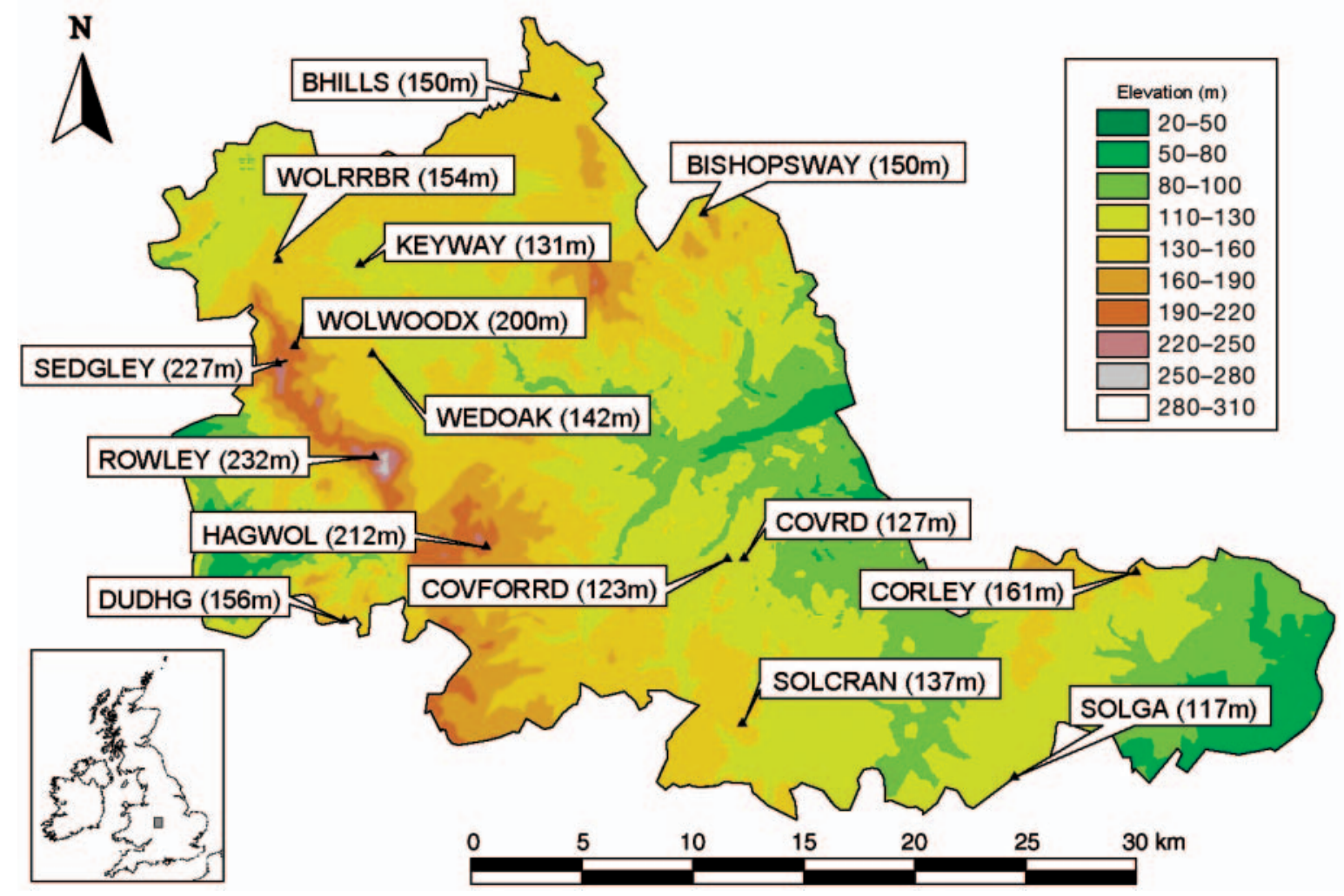

Fig. 1. Location of the West Midlands, the local topography and the location of the road weather sites used in this study 

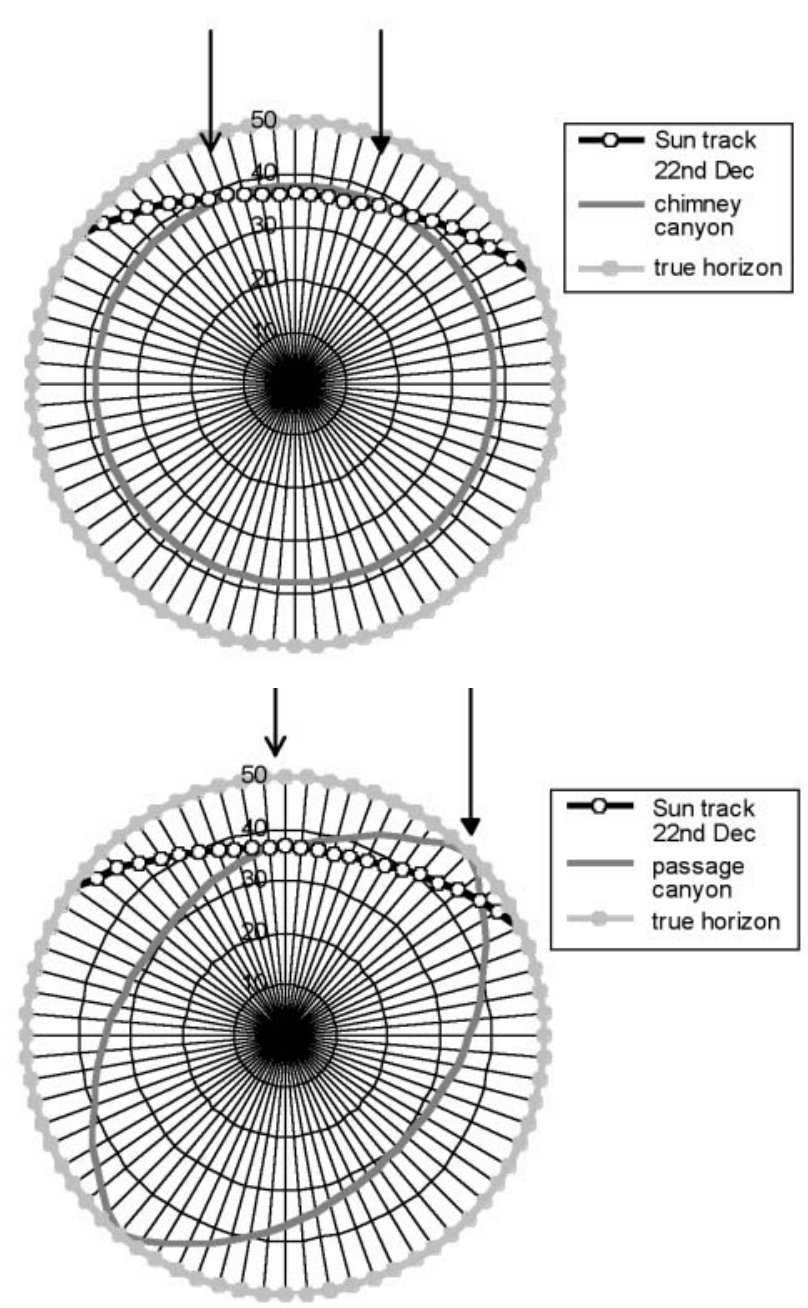

Fig. 2. Direct beam and direct diffusion for (a) 'chimney' (sunrise: 10:40 $h$; sunset: 13:40 h) and (b) 'passage' (sunrise: 12:00 $h$; sunset: 16:00 h) canyons on 22 December. Open arrow: effective sunrise; solid arrow: effective sunset

empirically derived SVF. Below an SVF of 0.2 there is a noticeable deviation, but this is considered acceptable as such SVFs are uncommon.

The SVF corresponds to the highest point of the artificial horizon; simple trigonometry is used to calculate the height of the horizon diminishing to the edges of the view (Fig. 2b). The artificial horizon was then oriented correctly according to the aspect of the road (e.g. NW to SE). The average orientation of the major road in each grid square was used. The model compares the building height (building zenith) with the sun height (solar zenith) for each segment (azimuth). If the solar zenith is less than the building zenith, direct beam radiation in the same azimuth is excluded and only diffuse radiation is included in the calculation. If the solar zenith is greater than the building zenith in the same azimuth, then both direct beam and diffuse radiation are included in the calculations. An in-depth discus- sion of these calculations, including the effect of vegetation, can be found in Chapman et al. (2001).

Outgoing LW radiation - For LW radiation, the SVF represents the proportion of open sky for which heat is radiated directly from the section of road being modelled. Hence the SVF is included in the LW emission from the ground, the value being used to weight the amount of radiation emitted, i.e.

$$
E=\psi_{\mathrm{sky}} \in \sigma T^{4}
$$

where $\in=$ emissivity, $E=$ energy emitted $\left(\mathrm{W} \mathrm{m}^{-2}\right), \psi_{\text {sky }}=$ SVF, $\sigma=$ Stefan-Boltzmann constant $\left(5.67 \times 10^{-8} \mathrm{~W} \mathrm{~m}^{-2}\right.$ $\mathrm{K}^{-4}$ ) and $T=\mathrm{RST}(\mathrm{K})$.

Optical depth. Using GIS altitude measurements of the West Midlands (Bartholomew data) the optical depth was corrected according to the UK Met Office handbook (1969):

$$
\begin{gathered}
m=h /(18429.1+67.53 T+0.003 h) \\
M=\operatorname{SLP}\left(10^{m}-1\right) \\
P=\operatorname{SLP}-M
\end{gathered}
$$

where $h=$ altitude $(\mathrm{m}), T=$ temperature $\left({ }^{\circ} \mathrm{C}\right)$ and SLP $=$ mean sea-level pressure $(\mathrm{mb})$.

Slope aspect and orientation. Slope aspect and orientation affect the incidence of solar radiation through the change in geometry of the surface. An adjustment was made to the solar beam subroutine to account for this; code changes were based on the following equations (Oke 1987, p. 345):

$$
\begin{gathered}
\cos \Theta=\cos \beta \cos Z+\sin \beta \sin Z \cos \left(\Omega-\Omega_{\mathrm{s}}\right) \\
S_{\mathrm{S}}=S_{\mathrm{i}} \cos \Theta
\end{gathered}
$$

where $\beta=$ slope angle, $Z$ = zenith angle, $\Omega\left(\Omega_{\mathrm{s}}\right)=$ solar (slope) azimuth, $\Theta=$ angle of incidence (between sun and slope normal) and $S_{\mathrm{S}}\left(S_{\mathrm{i}}\right)=$ direct solar radiation slope (normal incidence).

\subsubsection{Physical improvements}

The following variables are accounted for in the original model as constants. Using data from the West Midlands GIS (WMGIS) discussed in Section 2.2 below, for each of the 2400 cells, individual values could be substituted into the equations for these variables.

Albedo. Included in the solar generator, and varying with solar zenith according to Geiger (1965), the surface albedo at nadir is included in the statement

$$
\alpha=\alpha_{1}+0.131 Z^{4}
$$

where $\alpha_{1}=$ albedo at nadir, $\alpha=$ albedo (the albedo is never calculated to be greater than 1.0) and $Z=$ zenith angle (degrees). 
Emissivity. The calculated variation of emissivity of the surface is substituted in Eq. (1).

Roughness. The calculated variation of roughness was included in the statement to calculate the exchange coefficient, EXCO (Outcalt 1971):

$$
\mathrm{EXCO}=k^{2}\left\{\rho u /\left[\operatorname{alog}\left(z / z_{0}\right)\right]^{2}\right\}
$$

where $k=$ von Kármán constant $(0.4), \rho=$ air density $\left(\mathrm{kg} \mathrm{m}^{-3}\right), z=$ mixing height $(\mathrm{m}), z_{0}=$ roughness length (m) and $u=$ wind speed $\left(\mathrm{m} \mathrm{s}^{-1}\right)$.

The model was modified in 2 stages, firstly assessing the influence of the geographical variables and then secondly addition of the physical variables. A sensitivity analysis, using idealised forecast conditions, was carried out to identify the influence of each alteration. The performance of the model was then tested against real data acquired from sensor sites in the West Midlands study area.

\subsection{Calculating the variables for the $1 \mathrm{~km}^{2}$ grid}

In order to run the model for the $2400 \mathrm{~km}^{2}$ of the West Midlands, it is necessary to assign geographical and physical values for each $\mathrm{km}^{2}$. At the University of Birmingham and Birkbeck College, London, a GIS database of the West Midlands has been constructed for a Natural Research Environment Council (NERC), Urban Regeneration and Environment project. This database was queried to provide the following altitude and Landsat data:

- Bartholomew altitude data - provided information for geographic variables, altitude, slope angle and orientation. The modal (most common) value per $\mathrm{km}^{2}$ was calculated rather than the average scores per $\mathrm{km}^{2}$ because the altitude data has a $10 \mathrm{~m}$ resolution and average scores would not give the commonest slope angles and tend to cancel out the orientation of opposite slopes.

- Landsat image - provided spectral information on land cover to infer SVF, and the physical variables albedo, emissivity and roughness. This was aided by sampling in the field.

\subsubsection{Image analysis and classification}

The image available was a Landsat overpass taken in August 1996. An unrotated principal components analysis (PCA) was performed on the image (using ERDAS Imagine software) with a technique that was successful for urban areas in Leicestershire (UK; Langford et al. 1991). The percentage variance in each $\mathrm{PC}$ is shown in Table 1. PC 1 indicated $64 \%$ of the variance, roughly defining urban and rural areas; but PCs 2, 3
Table 1. Variance in each PC of a principal components analysis (PCA) on an image obtained from a Landsat overpass in August 1996

\begin{tabular}{|cc|}
\hline PC & \% contribution to variance \\
\hline 1 & 64.05 \\
2 & 16.59 \\
3 & 13.51 \\
4 & 4.55 \\
5 & 0.67 \\
6 & 0.53 \\
7 & 0.06 \\
\hline
\end{tabular}

and 4 indicated the internal structure of the urban areas, so they were deemed the most suitable for further classification and identification of land cover type within urban areas.

The eigenvalues of PCs 2, 3 and 4 indicate that most of the information is from the infra-red and near infrared bands 3 and 4, with a significant contribution from band 7 . This is a good source for contrasting non vegetated (band 7) and vegetated surfaces (bands 3 and 4), using the description of band combinations from Yesou et al. (1984).

Eight land cover classes (low-, medium- and highdensity residential areas, woodland, water, industrial buildings, large buildings and open spaces) were identified. The decision as to which land cover classes to select was partially pre-defined after consideration of classifications made by Morgen et al. (1977), Arnfield (1982) and Cionco \& Ellefson (1998). An unsupervised classification aided the decision, indicating the likely variation in spectral response over the image. Langford et al. (1991) found that reflectance from a large surface tends to saturate the pixel values. It was found in the West Midlands image that large industrial or retail units tended to have the same spectral signature as large office and tower blocks. This was overcome by identifying city-centre grid cells where large office and tower blocks were assumed to occur and assigning values for a typical central business district (CBD) area in the corresponding grid cells. The rest of the class was then assigned to have the characteristics of large industrial and retail buildings. The final classification resulted in the classified image shown in Fig. 3, which appears consistent with map verification and local knowledge of the area based on fieldwork.

\subsubsection{Field measurements of homogenous areas of each class}

The objective of the fieldwork was to sample the individual land cover classes and assign the corresponding canyon values of albedo, emissivity, rough- 


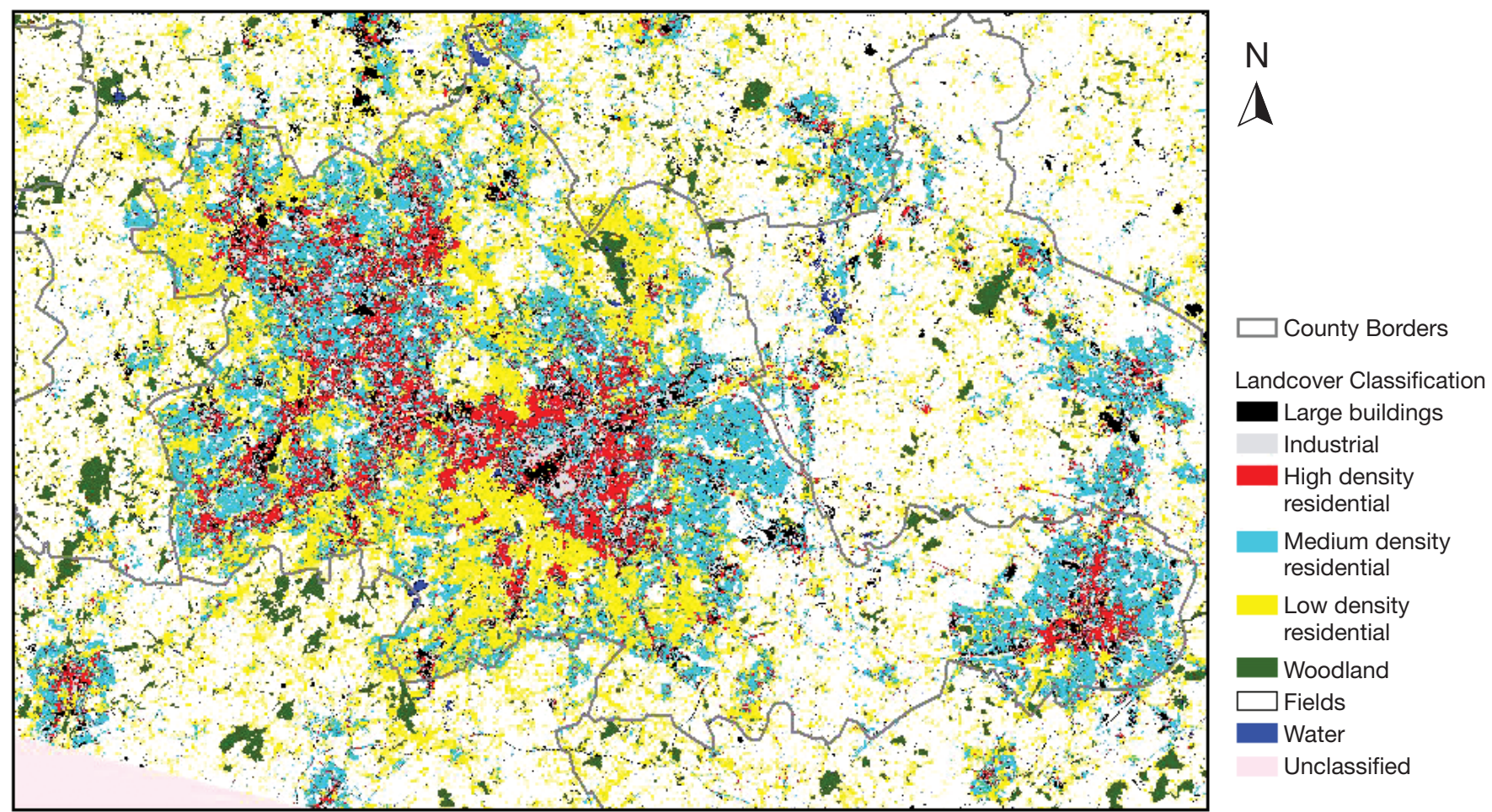

Fig. 3. Land cover classification of the West Midlands for August 1996, derived from PCA of a Landsat image $(\mathrm{area}=60 \times 40 \mathrm{~km})$

ness and SVF for each grid square. Large homogeneous areas for each land cover type were identified and sampled to represent all other pixels with the same classification on the image. The corresponding 1:10 000 OS map was used as a reference guide in the field. The sampling procedure used a street at each corner of the map from which all the elements were sampled.

\subsubsection{Canyon calculations}

Roughness length values $\left(z_{0}\right)$ were calculated using the following equation (Bottema 1997) selected from a review of methods by Grimmond \& Oke (1999):

$$
z_{\mathrm{d}}=\left\{\left[\sum A_{\mathrm{pb}}+\sum(1-p) A_{\mathrm{pt}}\right] / A_{\mathrm{T}}\right\}^{0.6} z_{\mathrm{H}}
$$

then

$$
\begin{aligned}
z_{0}= & \left(z_{\mathrm{H}}-z_{\mathrm{d}}\right) \exp \left[-0.4 /\left(0.5 \sum C_{\mathrm{db}} L_{\mathrm{ytb}} z_{\mathrm{Hib}}\right.\right. \\
& \left.\left.+\sum C_{\mathrm{dt}} L_{\mathrm{yit}} Z_{\mathrm{Hit}} / A_{\mathrm{T}}\right)^{0.5}\right] z_{\mathrm{H}}
\end{aligned}
$$

where $p=$ porosity of roughness elements (no units), $z_{\mathrm{d}}=$ zero plane displacement length $(\mathrm{m}), A_{\mathrm{T}}\left(A_{\mathrm{pb}}, A_{\mathrm{pt}}\right)=$ plan area terrain (buildings, trees) $\left(\mathrm{m}^{2}\right), z_{\mathrm{H}}=$ height of roughness elements $(\mathrm{m}), C_{\mathrm{db}}\left(C_{\mathrm{dt}}\right)=$ drag co-efficient for buildings, 0.8 (trees) (no units), $L_{\mathrm{ytb}}\left(L_{\mathrm{yit}}\right)=$ horizontal dimensions of buildings (trees) $(\mathrm{m}), z_{\mathrm{Hib}}\left(z_{\mathrm{Hit}}\right)=$ height of buildings (trees) (m) and $z_{0}=$ roughness length (m). Although the equation includes terms to represent vegetation, sampling of vegetation was excluded due to time constraints. The impact of trees with and without leaves is discussed in detail in Bradley et al. (2001).

The SVF was calculated from hemispherical images collected using the method outlined by Chapman et al. (2001). The average value was then calculated to represent the land cover type sampled (see Bradley et al. 2001).

To estimate the percentage of surface fabric, 2-D photographs of the sampled buildings were taken for each land cover class. Each photograph was overlaid with a grid, and the percentages of materials were then estimated for each facade. In order to represent proportions of typical fabrics of an element for each land cover type, all the facades sampled in that land cover class were averaged to create new representative values.

Using the street width calculations derived from fieldwork and the average building height for the land cover type, the dimensions of a typical urban canyon could be represented. According to the percentage representation of materials in that cross-section, it was possible to calculate the albedo and emissivity for the canyon. Table 2 indicates the values chosen for each material. The 'bulk' albedo and emissivity are calculated for each land cover class using the following expression: 


$$
\mathrm{LC}=\left[\sum_{1-n} j\left(k_{j} l_{j}\right)\right] / 100
$$

where LC = calculated emissivity (albedo) for land cover class, $j=$ material, $k=$ percent of material in the crosssection and $l=$ emissivity (albedo) for the material $j$.

The final values for each land cover class are given in Table 3. Note that trees have been given 2 SVF values: with foliage 0.3 and without foliage 0.9 (Bradley et al. 2001). This is an oversimplification, but the results below were all obtained for winter months, when it is assumed that there is no foliage.

Since each $1 \mathrm{~km}^{2}$ contains 729 land cover pixels (37 $\mathrm{m}$ resolution), it was necessary to sum the numbers of each land cover type per $\mathrm{km}^{2}$. The emissivity, albedo, roughness lengths and SVFs were recalculated according to the proportions of land cover type represented in that $\mathrm{km}^{2}$.

\section{RESULTS}

\subsection{Spatial distribution of variables derived from the land cover classification}

Fig. 4 displays the calculated values of the SVF, emissivity, albedo and roughness variables for each $\mathrm{km}$ square in the West Midlands. In general, the county is mostly built up with the exception of the rural division between Birmingham and Coventry (lower right of panels). For the SVF (Fig. 4a), in general the values are highest in the countryside $(0.9)$, decreasing through the suburbs (0.8), and lowest in the centre of built up areas (0.7). This is to be expected as urban canyons become deeper and more enclosed towards the centre of a conurbation. In Fig. 4b, the variation in emissivity is less clear, but lower values occur in the central urban areas (0.91), which are commonly substances with lower emissivity, mainly brick, concrete and glass. The higher values correspond to woodland and open spaces (0.94), as grass and trees have high emissivities. The pattern is less clear in suburban
Table 2. Assigned values for emissivity and albedo. All assigned values are from Obe (1987), except for grass albedo, which is from List (1958)

\begin{tabular}{|llll|}
\hline \multicolumn{2}{|c}{ Surface } & Emissivity & Albedo \\
\hline \multirow{6}{*}{ Ground } & Asphalt & 0.95 & 0.125 \\
& Grass & 0.93 & 0.205 \\
& Brick & 0.91 & 0.3 \\
& Concrete & 0.805 & 0.225 \\
& Wood & 0.9 & 0.15 \\
& Stone & 0.9 & 0.275 \\
& Glass & 0.895 & 0.305 \\
& Tile & 0.9 & 0.225 \\
& Slate & 0.9 & 0.1 \\
Roofs & Corrugated iron & 0.205 & 0.13 \\
Natural & Tar roof & 0.92 & 0.13 \\
& Forests & 0.97 & 0.15 \\
& Water & 0.97 & 0.5 \\
\hline
\end{tabular}

areas, where the land cover in each $\mathrm{km}^{2}$ is complex. In Fig. $4 \mathrm{c}$, albedo tends to be lowest in urban areas and highest in rural areas. In Fig. 4d, roughness appears strongly linked to urbanisation; the highest values occur in central urban areas (3.18 m), and values gradually decrease to the rural areas $(0.04 \mathrm{~m})$. This is due to the variations in density and height of elements which were used to calculate the roughness length. In general, as the elements become higher, so does the roughness value. There are some exceptionally high values for roughness, but these only correspond to a few $\mathrm{km}$ squares in the city centre. Some wooded areas show as mid-range values.

\subsection{Sensitivity analysis}

As winter road maintenance is of most direct concern to potential model users, a sensitivity analysis for the winter period is presented using a forecast likely to produce freezing RSTs. The weather conditions chosen are no cloud cover and low wind speed, typical

Table 3. Final estimates for land cover classes. SVF: sky-view factor; CBD: central business district; LB: classification of large buildings by image processing

\begin{tabular}{|c|c|c|c|c|c|c|}
\hline Class & Description & Height (m) & Roughness (m) & Albedo & Emissivity & SVF \\
\hline 1 & Medium-density residential & 6.37 & 0.94 & 0.19 & 0.93 & 0.89 \\
\hline 2 & High-density residential & 7.46 & 0.91 & 0.20 & 0.94 & 0.82 \\
\hline 3 & Low-density residential & 5.25 & 0.34 & 0.21 & 0.93 & 0.86 \\
\hline 4 & Industrial & 8.99 & 1.06 & 0.22 & 0.90 & 0.75 \\
\hline 5 & Woodland & 12 & 1.00 & 0.15 & 0.97 & $0.3^{\mathrm{a}} / 0.90^{\mathrm{b}}$ \\
\hline 6 & Water & 0.01 & 0.01 & 0.50 & 0.97 & 0.99 \\
\hline 7 & Industrial (LB) & 7.25 & 0.53 & 0.16 & 0.85 & 0.86 \\
\hline 8 & Open & 0.1 & 0.04 & 0.21 & 0.93 & 0.94 \\
\hline 9 & CBD (LB) & 20.69 & 3.56 & 0.23 & 0.90 & 0.72 \\
\hline
\end{tabular}


of Pasquill-Gifford stability class ' $G$ ' with air temperature forecast to fall below zero. The model was run for the dates of 31 October and 31 March, covering the beginning and the end of the UK winter road maintenance period. To cover the minimum solar radiance, a run for the shortest day, 22 December was also included. Each new additional variable to the model was tested to examine the magnitude of the signal in the model output. The choice of values used represented the maximum and minimum values of each variable calculated from the land cover classification. Table 4 shows the variation in maximum and minimum RST range for each variable for 22 December and 31 March.
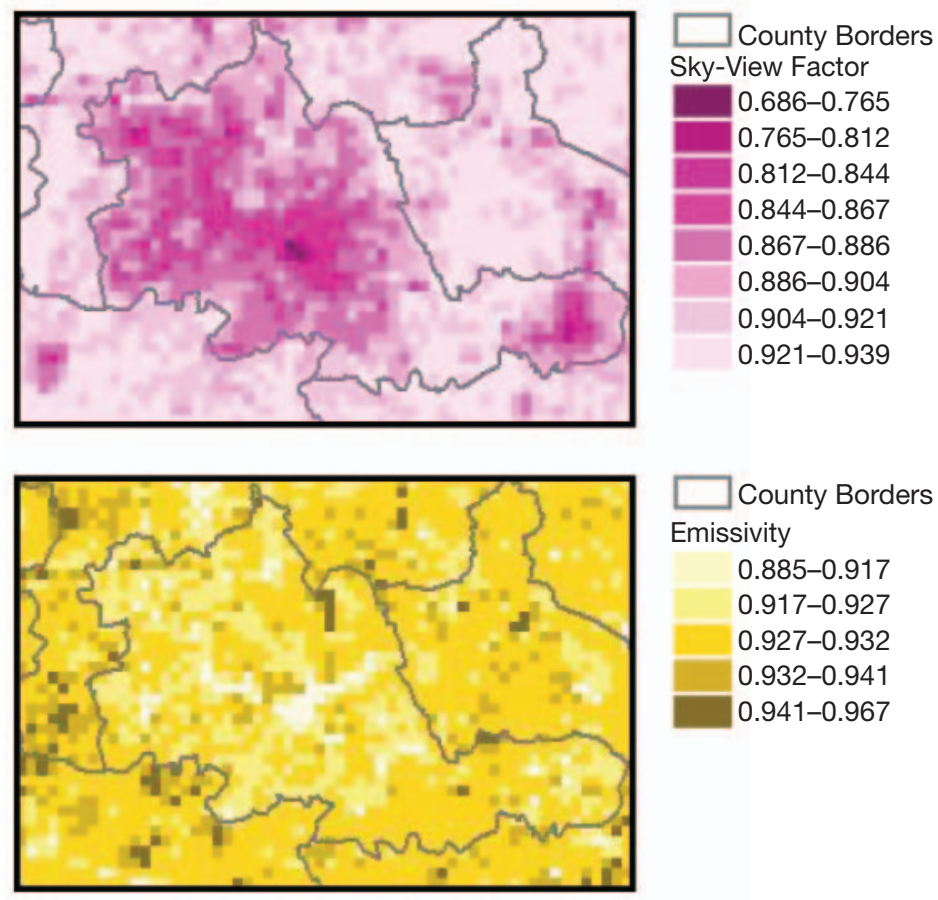

County Borders Emissivity

$0.885-0.917$

$0.917-0.927$

$0.927-0.932$

$0.932-0.941$

$0.941-0.967$

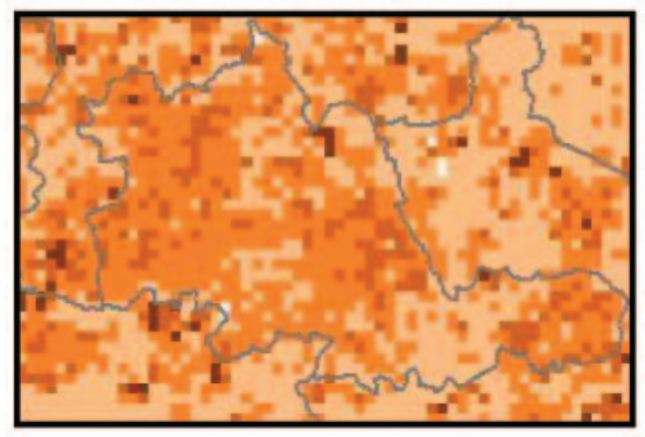

County Borders

Albedo
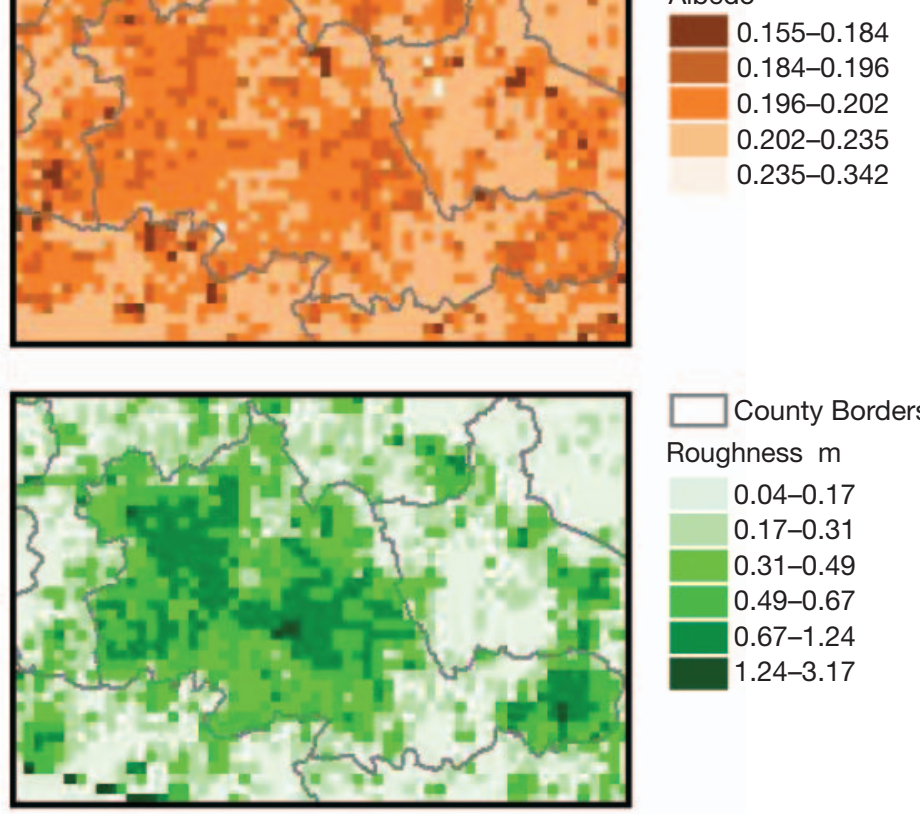

County Borders

Roughness $\mathrm{m}$

$0.04-0.17$

$0.17-0.31$

$0.31-0.49$

$0.49-0.67$

$0.67-1.24$

$1.24-3.17$

Fig. 4. Distribution of model variables for the West Midlands grid model (each square represents $1 \mathrm{~km}^{2}$ )

\subsubsection{Geographical variables}

Latitude. Latitude varies between $52^{\circ} 41^{\prime} 4.7^{\prime \prime}$ and $52^{\circ} 19^{\prime} 47^{\prime \prime} \mathrm{N}$ over the study area. This produces a maximum road temperature variation of $0.35^{\circ} \mathrm{C}$ during March (Table 4), when solar radiation is strongest, and $0.14^{\circ} \mathrm{C}$ in December, when solar radiation is weakest. When the sun has set and no longer contributes to the model, the difference in night-time minima is negligible.

Optical depth. As the altitude range over the West Midlands is small $(<250 \mathrm{~m})$, optical density caused only a small variation $\left(>0.06^{\circ} \mathrm{C}\right)$.

Slope. This is a comparison of north versus south slopes, to show the most extreme differences since the sun resides in the southern sky. The steeper slope angles yield warmer surfaces as slope angles become more normal to the sun zenith angle. The RST differences are much smaller during the night as there is no input of solar radiation. However, warmer slopes influence the timing of road freezing because the additional heat is stored in the road and they remain relatively warmer than shallower slopes.

SVF. SVF was included in the calculation of LW radiation to represent the proportion of open sky for which energy is exchanged from the ground and air via thermal emission. Thus a proportional amount of energy is retained according to the SVF. It has also been included for the reception of SW radiation, to account for restriction of diffuse and direct beam radiation to a surface. This is a rough approximation as the resolution of $1 \mathrm{~km}$ grid squares cannot account for point-specific shadow complexities of an individual road. Table 4 indicates that SVF retains a similar variation on night-time RSTs throughout the winter, thus LW emission is proportional to the SVF. In the day, RST ranges are wider, greatest in March when the SW input is greater due to higher solar zeniths. Interestingly enough, higher (more open) SVFs are warmer, illustrating how shadowing in enclosed SVFs reduces input of SW radiation. 
Table 4 . Road surface temperature $\left(\mathrm{RST}_{;}{ }^{\circ} \mathrm{C}\right)$ range differences of daily maxima and minima for 22 December and 31 March during the sensitivity analysis

\begin{tabular}{|c|c|c|c|c|c|}
\hline \multirow{2}{*}{ Variable } & \multirow{2}{*}{ Range } & \multicolumn{2}{|c|}{$22 \mathrm{Dec}$} & \multicolumn{2}{|c|}{31 Mar } \\
\hline & & Daily max & Night min & Daily max & Night min \\
\hline \multicolumn{6}{|c|}{ Geographical variables } \\
\hline \multirow[t]{2}{*}{ Latitude } & $52^{\circ} 41^{\prime} 4.7^{\prime \prime}$ & - & & & \\
\hline & $52^{\circ} 19^{\prime} 47^{\prime \prime}$ & 0.14 & 0.02 & 0.35 & 0.02 \\
\hline Optical depth & $20-260 \mathrm{~m}$ & 0.02 & 0 & 0.06 & 0.01 \\
\hline Slope $0^{\circ}$ & $(\mathrm{N}$ vs $\mathrm{S})$ & 0 & 0 & 0 & 0 \\
\hline Slope $10^{\circ}$ & $(\mathrm{N}$ vs S) & 0.67 & 0.06 & 7.93 & 0.53 \\
\hline Slope $20^{\circ}$ & $(\mathrm{N}$ vs S) & 2.74 & 0.1 & 15.75 & 1.07 \\
\hline Slope $30^{\circ}$ & (N vs S) & 3.42 & 0.14 & 23.39 & 1.57 \\
\hline SVF & $1.0-0.5$ & 1.68 & 2.19 & 5.67 & 2.26 \\
\hline \multicolumn{6}{|c|}{ Physical variables } \\
\hline Emissivity & $0.88-0.96$ & 1.91 & 1.85 & 2.05 & 1.85 \\
\hline Albedo & $0.15-0.34$ & 1.82 & 0.1 & 5.78 & 0.55 \\
\hline Roughness & $4-317 \mathrm{~cm}$ & 1.63 & -0.7 & 19.74 & 2.11 \\
\hline
\end{tabular}

Shading. During the daytime, direct beam SW radiation is shaded from the road surface if the sun is obstructed by the canyon walls. In the model when such an obstruction occurred only diffuse radiation is included in the calculations. The time at which shading effects occur depends on the orientation of the canyon. Table 5 shows how the model replicates this for the daily maximum difference. The seasonal difference is emphasised by a $0.15^{\circ} \mathrm{C}$ range between the $\mathrm{N}-\mathrm{S}$ and $\mathrm{E}-\mathrm{W}$ maxima in December, compared with a $1.61^{\circ} \mathrm{C}$ range between the N-S and E-W maxima in March. The model also simulates RSTs in NW-SE canyons to be slightly warmer than NE-SW canyons. This is because, in the former case, direct beam radiation strikes the road surface earlier than the latter case, where at a similar time the sun is simulated to be behind buildings. As this influences solar radiation during the day, effects are negligible at night for the solar minimum.

\subsubsection{Physical variables}

Emissivity. Variations in emissivity change the modelled road temperatures by $1.85^{\circ} \mathrm{C}$ at night (Table 4). This is seasonally constant as during the night there is no solar radiation. In the daytime, a seasonal variation is apparent which causes a difference of $0.14^{\circ} \mathrm{C}$ between the December and March maxima, simply due to the lower output of LW radiation simulated by the model in winter.

Albedo. Albedo causes the largest variation during the day and also responds seasonally, the greatest differences occurring in March. As the calculation is included in the solar generator, it will have no influence on the night-time RST calculations, although higher daytime RSTs propagate into warmer night-time RSTs, hence the small displacement of values at minimum, e.g. only $0.55^{\circ} \mathrm{C}$ in March.

Roughness. The magnitude of the RST differences varies seasonally, with the March run producing the greatest differences. In the diurnal sequence, the extremes of values are greatest during the daytime, and least at night. This is due to the variation in stability during the $24 \mathrm{~h}$ sequence. Stability is described by the Richardson number, which influences the stability correction factor in the model. For extreme conditions during the day, the air is described as being mostly unstable, and during the night, more stable. The model loads this on to the sensible and latent heat fluxes, which include the roughness value. The roughness value in turn influences the damping height at which thermal forces overcome adiabatic forces. As the roughness value increases, the damping height increases. The RST is thus greater because loss of energy is reduced in the radiation balance. However in extreme conditions for December, the model actually calculates stable air. This makes the adiabatic forces much weaker against the thermal forces at the damping height (because of the stable conditions). Thus the model produces a decrease in RST with higher roughness values. This causes the small negative difference in December. The calculation of roughness and its use in the model still requires further research.

Table 5. Maximum and minimum RSTs for an SVF of 0.7

\begin{tabular}{|lcccc|}
\hline Simulated canyon orientation & $\begin{array}{c}\text { 22 Dec } \\
\text { Daytime max }\end{array}$ & $\begin{array}{c}\text { 22 Dec } \\
\text { Night-time min }\end{array}$ & $\begin{array}{c}31 \text { Mar } \\
\text { Daytime max }\end{array}$ & $\begin{array}{c}31 \text { Mar } \\
\text { Night-time min }\end{array}$ \\
\hline N-S & 10.91 & 4.17 & 34.29 & 6.11 \\
NW-SE & 10.74 & 4.17 & 35.55 & 6.28 \\
E-W & 11.06 & 4.18 & 35.90 & 6.33 \\
NE-SW & 10.56 & 4.16 & 35.46 & 6.22 \\
\hline
\end{tabular}




\subsection{Model validation and analysis}

Our degree of confidence in the quality of the model can be evaluated by testing the accuracy of the model against road sensor measurements. Using daily forecast data, the model was used to predict RSTs up to $24 \mathrm{~h}$ ahead for each day from 1 December 1999 to 29 February 2000. The forecast meteorological data were taken from the OR forecast supplied to the West Midlands councils. Sedgley Ridge (Fig. 1) was chosen as the forecast site as this has the coldest or most pessimistic forecast for the West Midlands. The accuracy of the model has been tested in 2 ways using output generated from forecast data:

(1) Forecast performance against the Meteorological Office model: Comparison of the West Midlands Grid model with an existing RST model to examine the performance in the prediction of RST for individual nights at 1 spot location. Data for 79 days/nights in the period were analysed when a full data set was available.

(2) Spatial output: There are 15 OR weather sensors in and around the West Midlands (Fig. 1) which supply hourly data on RST amongst other meteorological factors. From this data the complete daily performance of the model can be estimated at these locations and the results of spatial outputs can be analysed. The results also allow an analysis of UHI intensity to be estimated with respect to variations in SVF. Data for the month of February 2000 were analysed.

\subsubsection{Comparison of WMG with the Meteorological Office model (MOM)}

The model was run for each day using the Sedgley Ridge forecast. SVF was adjusted for the Sedgley Ridge site from the $\mathrm{km}$ square value of 0.8671 to 0.95 because the road sensor site is positioned in an open area. The forecast minimum RSTs for WMG and MOM was archived together with the sensor site data. Fig. 5 shows how both models follow the RST trends measured at the sensor site. Fig. 6 shows that the performance of the WMG and MOM is similar, but with $\mathrm{R}^{2}$ values of 0.62 and 0.50 respectively.

For the 79 nights, the root mean square error (RMSE) for $\mathrm{MOM}$ is $3.09^{\circ} \mathrm{C}$ and the bias is $-2.03^{\circ} \mathrm{C}$. For $\mathrm{WMG}^{\circ}$ the RMSE is $2.07^{\circ} \mathrm{C}$ and the bias is $+0.65^{\circ} \mathrm{C}$. Thornes \& Shao (1991) found that MOM has a negative bias of $>1^{\circ} \mathrm{C}$ and the model WMG is derived from tended to have a positive bias of around $0.5^{\circ} \mathrm{C}$. The likely causes of these differences are that MOM is constructed to give a pessimistic forecast for the highway engineers, whereas WMG has been constructed to simulate warmer urban road conditions. These results show that WMG has a lower RMSE and smaller bias than MOM, which is promising (Thornes \& Stephenson 2001), but that the positive bias needs to be removed.

\subsubsection{Validation for spatial output}

This validation procedure involved matching the road weather sensor sites with the corresponding West Midlands grid square. The SVF was not adjusted in this comparison. The hourly output for a single site, Brownhills, over the month of February is shown in Fig. 7. The day-to-day diurnal changes in RST are well replicated throughout the month, with a few exceptions. When the sensor output is plotted against the model output for each individual site the $\mathrm{R}^{2}$ value commonly falls between 0.84 and 0.73 (Table 6).

The model is therefore replicating the diurnal trends and daily variations in RSTs, although the actual timing and magnitude of the RSTs are not precise. The differences are due to a number of reasons. Firstly, there is the accuracy of the input data from the forecast such as cloud cover, air and dew point temperatures. Cloud forecasts are the most unreliable input because of their



Fig. 5. Comparison of daily minimum RSTs $\left({ }^{\circ} \mathrm{C}\right)$ for December 1999 to February 2000 for the Meteorological Office model (MOM) and the West Midlands grid model (WMG) 


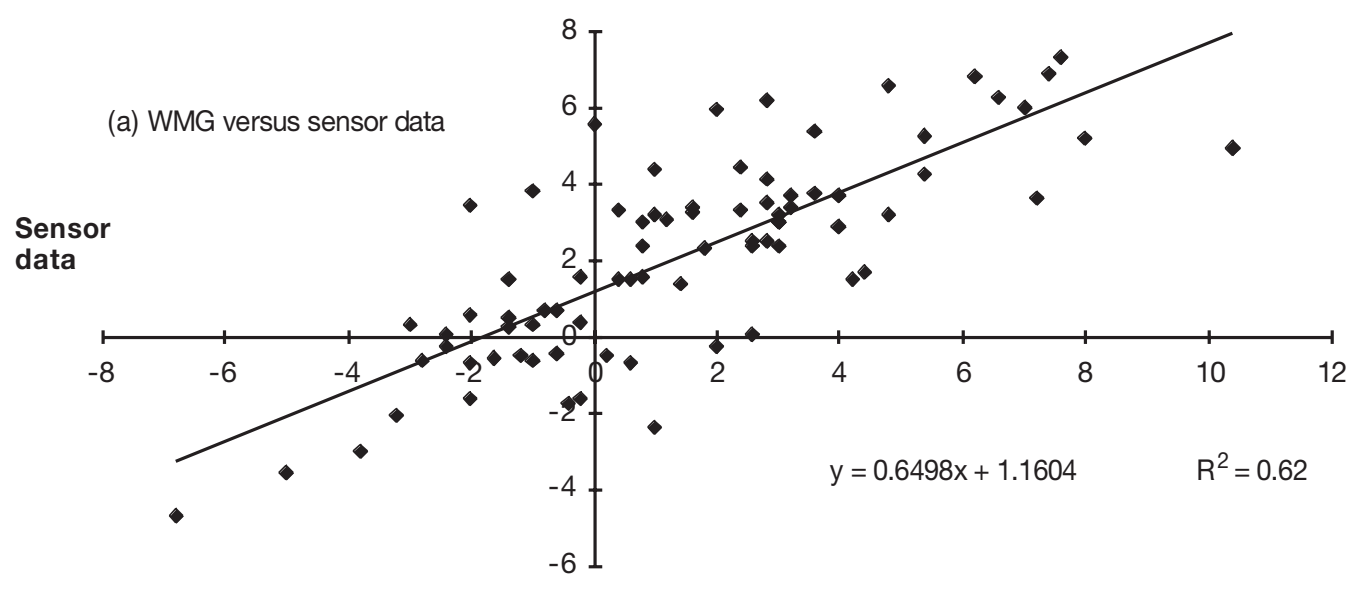

Model Data

Fig. 6. Daily minimum RST $\left({ }^{\circ} \mathrm{C}\right)$. (a) WMG vs. sensor; (b) MOM vs. sensor

rapidly changing nature. Secondly, the variables fed into the model represented values calculated for a whole $\mathrm{km}^{2}$ rather than a single sensor site. It would be possible to include site-specific variables for each sensor site, but this similarly does not represent RSTs for the whole area. In order to be consistent, a site for each $\mathrm{km}^{2}$ would have to be chosen and sampled to give a value for each model variable. A good example of the difference between a sensor site forecast and a $1 \mathrm{~km}^{2}$ forecast is highlighted by the model simulation of a parallel uniform urban canyon. If a site-specific sample is measured, because of the complexities of individual building heights and shading at a sensor site, the determination of diffuse and or direct beam radiation can only be estimated for 1 street orientation. In the model, the street orientation can be adjusted, thus allowing for determination of diffuse and or direct beam radiation for any street in that $\mathrm{km}^{2}$. Lastly there are variables which the model does not directly account for such as traffic, which will normally increase RSTs.
Table 6. $\mathrm{R}^{2}$ values for 15 OR sites and WMG output for RST during the 29 nights of February 2000

\begin{tabular}{|lc|}
\hline Sensor site & $\mathrm{R}^{2}$ \\
\hline Brownhills & 0.80 \\
Wolverhampton Bilston Road & 0.74 \\
Keyway & 0.79 \\
Sedgley & 0.80 \\
Wednesbury Oak & 0.81 \\
Rowley Regis & 0.79 \\
Hagley Wolverhampton Road & 0.81 \\
Coventry Road & 0.60 \\
Solihull Cranmore & 0.81 \\
Solihull Garage & 0.82 \\
Dudley Hayley Green & 0.80 \\
Corley & 0.74 \\
Bishopsway & 0.84 \\
Coventry Ford Road & 0.78 \\
Wolverhampton Wood Cross & 0.83 \\
Average & 0.78 \\
\hline
\end{tabular}






Fig. 7. Monthly comparison of Brownhills' actual RST $\left({ }^{\circ} \mathrm{C}\right)$ with WMG

\subsection{The UHI intensity for RSTs}

To establish the extremes of RSTs over the West Midlands, the surface UHI intensity has been estimated. This is the RST difference between a rural and urban site. The model was run for 22 December, when solar input is at a minimum.

Fig. 8 shows a typical transect through the model, which cuts through the city centre of Birmingham. There is a single peak of $4.62^{\circ} \mathrm{C}$ which corresponds to the CBD. The transect is analogous to the cliff, plateau, peak structure of the air temperature UHI (Oke 1987), giving an UHI intensity of $4.69^{\circ} \mathrm{C}$.

Fig. 8 also indicates the possible spatial RST ranges that may occur in a single night. For instance, in December using the model values, the forecast RST would have to drop to $-4.69^{\circ} \mathrm{C}$ for the whole rural and urban area to require salting. If this does not happen, then there is scope for identifying the ranges of RSTs across the West Midlands urban area for a more efficient salting strategy. The example in Fig. 8 represents a transect in a single time window at 01:00 h. The temporal development and spatial variation in RSTs can be examined if a number of time slices from a single night are investigated. Using a real forecast for the night of 21 February 2000, an example of this can be seen in Fig. 9.

For each time slice, there are a number of features which indicate the generation and internal complexities of an UHI. Examining the 05:00 $\mathrm{h}$ time slice from Fig. 9, the warm urban core of $1.5^{\circ} \mathrm{C}$ is surrounded by suburban regions which are slightly cooler, 0 to $1^{\circ} \mathrm{C}$. The cooler rural areas $\left(<0^{\circ} \mathrm{C}\right)$ surround the urbanised zones. This indicates that there is considerable spatial variation of RST between rural and urban areas. Within the urbanised zone, a complex structure and variation of RST is apparent: a cause of the ranges of variables calculated from the land cover classification. Where the variables represent more urban zones, the RSTs are comparatively warmer than the rural surroundings.

Temporally, this has important implications for forecasting the timing and location of RSTs, when they fall below zero and the extent to which this pattern follows the existing forecast zones. The rural area cools quickest and drops below zero first (Fig. 9). Conversely, the urbanised area or core is warmest and, in this particular case, never falls below zero. There is a spine of warmer RSTs in the conurbation which also remains above zero. Some of the suburbs eventually fall below zero but much later than the rural areas. If an existing forecast zone is focused on, it is apparent that as the night progresses the RSTs within some forecast zones are variable. The RSTs within a forecast zone should be reasonably uniform and consistent. This is clearly not the case. From this information it is suggested that

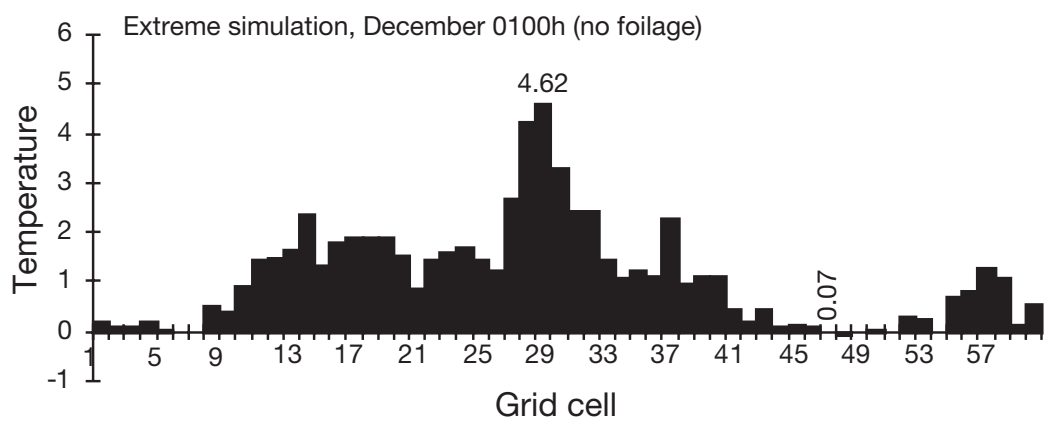

Fig. 8. Simulated RST $\left({ }^{\circ} \mathrm{C}\right)$ for an E-W transect through Birmingham city centre at $01: 00 \mathrm{~h}$ 
0100h

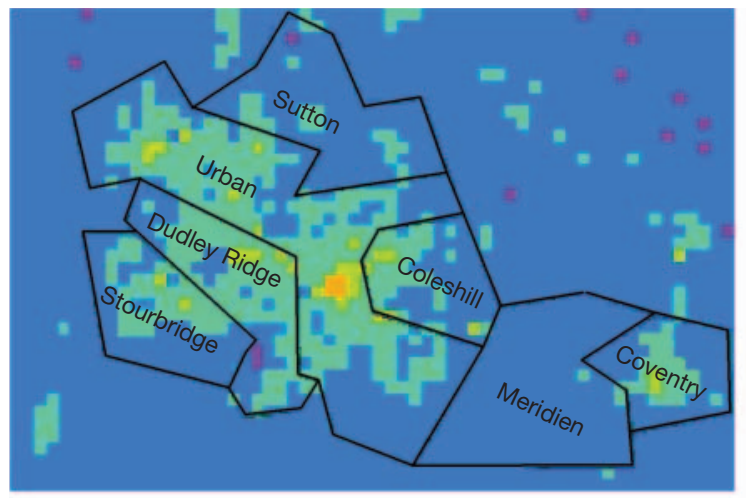

0500h

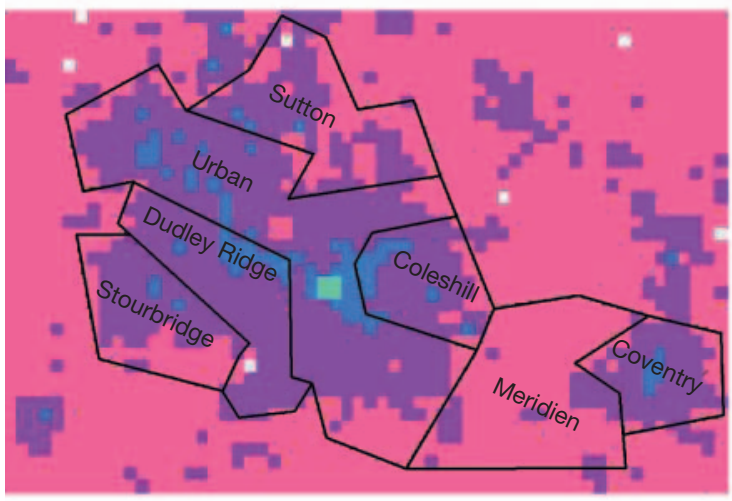

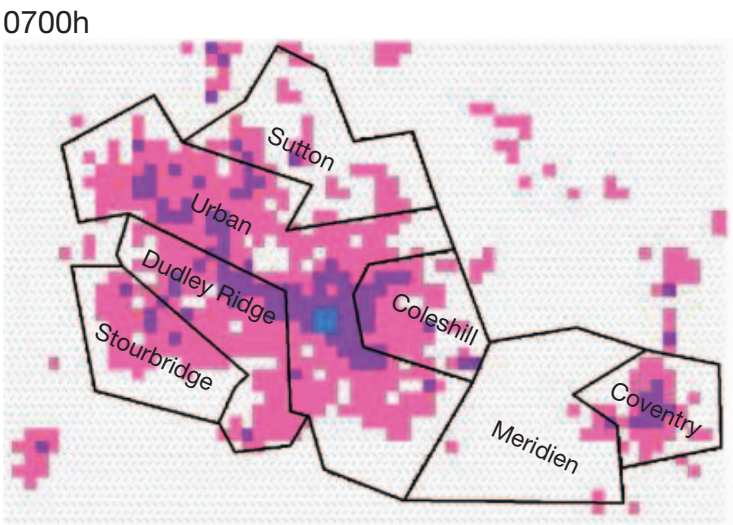

\begin{tabular}{|c|c|}
\hline & OR Forecast Zones \\
\hline Temp & $\begin{array}{l}\text { perature: Degrees C } \\
-5--0.25\end{array}$ \\
\hline & $-0.25-0$ \\
\hline & $0-0.5$ \\
\hline & $0.5-1$ \\
\hline & $1-1.5$ \\
\hline & $1.5-2$ \\
\hline & $2-2.5$ \\
\hline & $2.5-3$ \\
\hline & $3-5$ \\
\hline
\end{tabular}

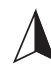

$\mathrm{N}$
Scale:

1 square $=1 \mathrm{~km} \times 1 \mathrm{~km}$

Fig. 9. Times slices generated by WMG for 21 December at 01:00, 05:00 and 07:00 h

RST forecast zones should be defined around the bounds of urbanisation and the degree of urbanisation (canyon size and extent of urban suburbs buffering the urban core), with a surrounding rural zone which is influenced by topographic variation. Fig. 10 suggests such a simplified scheme. However it should be noted that climate zones are totally unnecessary if a forecast is made for each $\mathrm{km}$ square.

\section{CONCLUSIONS}

The method described shows how values for albedo, sky-view factor, and roughness can be derived for any urban or rural grid. The proportional averaging of variables within each $\mathrm{km}^{2}$ appears to relate well to the variability in land cover. This ensures that the likelihood of a similar combination of values occurring between any $1 \mathrm{~km}^{2}$ grid squares is vastly reduced, increasing the range of calculated road surface temperatures.

The most influential of the variables was the weighting of surface emission with a sky-view factor. As well as being a new input, sky-view factor values had a wide range, hence broadening the differences in road surface temperature output giving noticeably warmer values in enclosed areas such as the central business district. The variables emissivity and albedo were less influential, and roughness still requires further research.



Fig. 10. Conceptualised urban-rural forcast zones with the current OR climate zones superimposed 
The WMG model forecast was generally warmer than actual sensor data by $0.65^{\circ} \mathrm{C}$, although replication of hourly data kept pace with diurnal road surface temperature trends to give $\mathrm{R}^{2} \sim 0.75$ to 0.8 . Since the skyview factor was the most dominant variable, it is suggested MOM may be improved with the inclusion of this term, as this model tends to be too cool. It is possible to simulate the contrast of rural and urban road surface temperatures and the internal complexities of the road surface temperature urban heat island. Analysis of the distribution of the road surface temperatures in space and time indicated a poor relationship with the current Open Road forecast zones for extreme conditions. This leads to the conclusion that Open Road forecast zones can be improved upon, i.e. a road surface temperature forecast should be related more towards the degree of urbanisation, superimposed on topographic effects.

It is apparent that the model output is extremely sensitive to the initial values supplied in the forecast. It was assumed that all starting road surface temperatures are the same over the study area, so the model is calculating from the same forecast temperatures of surface, air and dew point for every individual grid square across the West Midlands. Including a correction for altitude may overcome this, but the addition of environmental lapse rates to the model is a complex issue in itself, partially due to topographic complexities which may lead to katabatic air flows. It is beyond the capabilities of this 1-D model to simulate lateral interaction between the $1 \mathrm{~km}^{2}$ grid cells; a more complex model may overcome this.

One of the aims of the simulation was to include the influence of urban canyon characteristics on the road surface. This took on the basic assumption that the internal structure of the walls was similar to a road surface because the model is constructed to calculate road surface temperature in equilibrium with the ground. The canyon characteristics had the least influence on the model; albedo and emissivity played a minor role because they were very close to the model default values of 0.2 and 0.95 respectively. A most useful development in the model would be to include multiple reflection, absorption and re-emission from the canyon walls to the road surface using the estimated canyon dimensions and a sky-view factor as a surrogate to increase or decrease these events.

Other variables which need to be explored include the influence of traffic. It is suggested that the busier a stretch of road the more likely it is to have a higher road surface temperature and smaller diurnal range. Ideally, real time data for volumes of traffic for certain times of day and week, to cover the contrast of rush hour daytime and quiet night-time traffic volumes, should be examined.
Acknowledgements. We would like to thank Dr. Glenn McGregor for assistance with the PCA analysis, Dr. Xiaoming Cai for help with the sky-view factor analysis and Ye Ping Tsim for fieldwork and calculations of roughness values in the West Midlands. We would also like to thank the Natural Environment Research Council (NERC) for their NERC URGENT grant support (GST/02/1971).

\section{LITERATURE CITED}

Arnfield AJ (1982) An approach to the estimation of the surface radiative properties and radiation budgets of cities. Phys Geogr 3(2):97-122

Arnfield AJ (1990) Canyon geometry, The urban fabric and nocturnal cooling: a simulation approach. Phys Geogr 11: 220-239

Bärring L, Mattssonn JO, Lindquist S (1985) Canyon geometry, street temperatures and urban heat island in Malmo, Sweden. J Climatol 5:433-444

Bogren J, Gustavsson T, Karlson IM, Postgård U (2000) The impact of screening on road surface temperature. Meteorol Appl 7(2):97-104

Bottema M (1997) Urban roughness modelling in relation to pollutant dispersion. Atmos Environ 31:3095-3075

Bradley A, Thornes JE, Chapman L (2001) Variation and prediction of urban canyon geometry from sky-view factor transects. Atmos Sci Lett; available at http://www. idealibrary.com/links/doi/10.1006/asle.2001.0031

Cionco RM, Ellefson R (1998) High resolution urban morphology data for urban wind flow modelling. Atmos Environ 32:7-17

Chapman L, Thornes JE, Bradley AV (2001) Rapid determination of canyon geometry parameters for use in surface radiation budgets. Theor Appl Climatol 69:81-89

Geiger R (1965) The climate near the ground. Harvard University Press, Cambridge, MA

Greene G (1980) Testing an urban climate simulator. US Geological Survey Professional Paper 1099-E, United States Government Printing Office, Washington, DC

Grimmond CSB, Oke TR (1999) Aerodynamic properties of urban areas derived from analysis of surface form. J Appl Meteorol 38:1262-1292

Grimmond CSB, Potter SK, Zutter HN, Souch C (2001) Rapid methods to estimate sky-view factors applied to urban areas. Int J Climatol 21(7):903-913

Gustavsson T, Bogren J (1993) Evaluation of a Local Climatological Model-test carried out in the county of Halland, Sweden. Meteorol Mag 122(1456):257-267

Langford M, McGuire DJ, Unwin DJ (1991) The areal interpolation problem: estimating population using remote sensing in a GIS framework. In: Masser I, Blakemore M (eds) Handling geographical information: methodology and applications. John Wiley and Sons, New York, p 55-77

List RJ (1958) Smithsonian meteorological tables, 6th rev. edn. Smithsonian Institution, Washington, DC, 114(4014)

McClean AA (1993) The evaluation and modification of a prediction model for road surface temperatures. MSc thesis, Dept of Geography, University of British Columbia, Vancouver

Mills G (1997) An urban canopy-layer climate model. Theor Appl Climatol 5:229-244

Morgen G, Myrup L, Rodgers D, Baskett R (1977) Microclimates within an urban area. Ann Assoc Am Geogr 67(1):55-65

Oke TR (1981) Canyon geometry and the nocturnal heat island: comparison of scale model and field observation. J Climatol 1:237-254 
Oke TR (1987) Boundary layer climates. Methuen, London

Outcalt S (1971) A numerical surface climate simulator. Geogr Anal 3:379-393

Postgård U (2000) Road climate variation related to weather and topography. PhD thesis, A52GU2000, Department of Physical Geography, University of Göteborg

Rayer PJ (1987) The meteorological forecast road surface temperature model. Meteorol Mag 116:180-191

Swaid H (1993) Numerical investigation into the influence of geometry and construction materials on urban climate. Phys Geogr 14:342-358

Tapper NJ, Tyson PD, Owens IF, Hastie WJ (1981) Modelling the winter urban heat island over Christchurch, New Zealand. J Appl Meteorol 20(4):365-376

Editorial responsibility: Clare Goodess,

Norwich, United Kingdom
Thornes JE (1984) The prediction of ice formation on motorways. PhD thesis, University of London

Thornes JE, Shao J (1991) A comparison of UK road ice prediction models. Meteorol Mag 120(1424):51-57

Thornes JE, Stephenson D (2001) How to judge the quality and value of weather forecast products. Meteorol Appl 8(3):307-314

Thornes JE, Sugrue G, Osborne R (1983) Thermal mapping of road surface temperatures. Phys Technol 14:212-213

UK Meteorological Office (1969) Observer's handbook. HMSO, London

Yesou H, Besnus Y, Rolet J (1984) Extraction of spectral information from Landsat TM data and merger with SPOT panchromatic imagery. J Photogram Remote Sensing 48(5):23-36

Submitted: February 28, 2001; Accepted: September 17, 2001 Proofs received from author(s): June 17, 2002 